UCRL-ID-134254

\title{
A Conceptual Design for an Electron Beam
}

\author{
Manuel Garcia
}

February 15, 1999

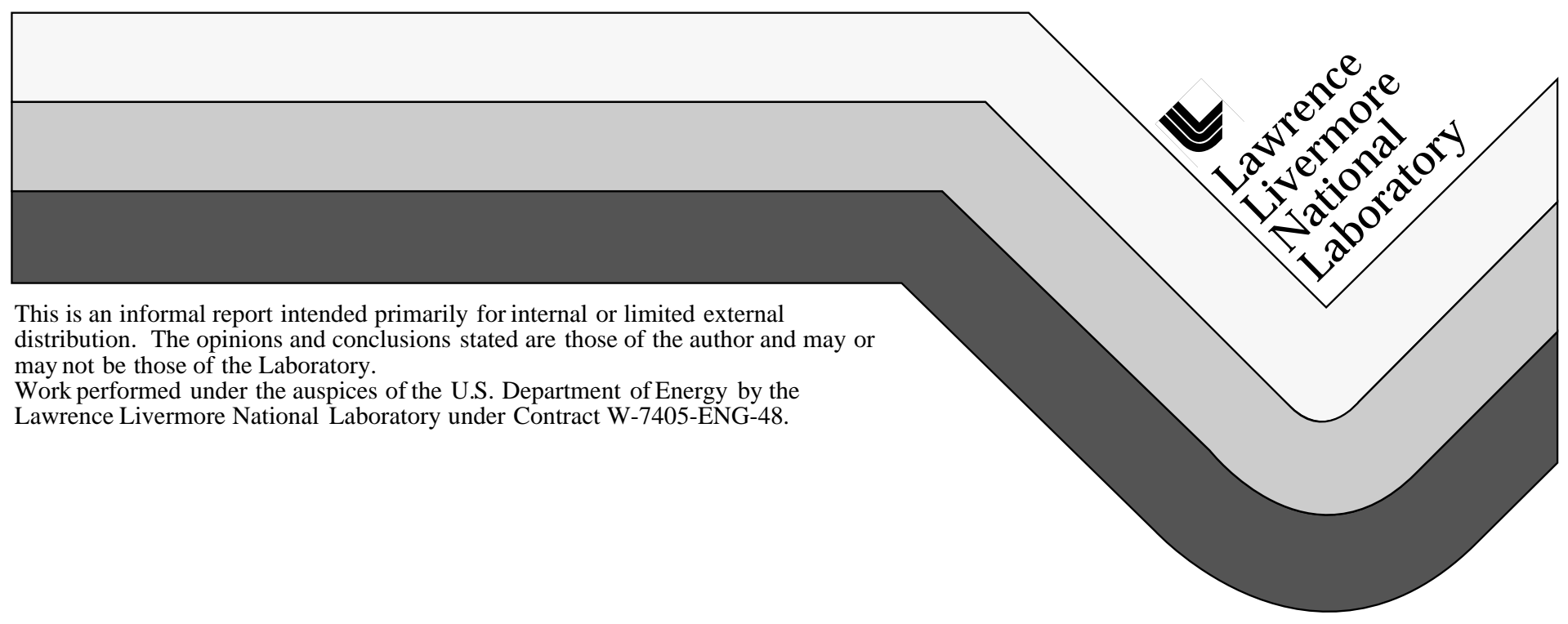




\section{DISCLAIMER}

This document was prepared as an account of work sponsored by an agency of the United States Government. Neither the United States Government nor the University of California nor any of their employees, makes any warranty, express or implied, or assumes any legal liability or responsibility for the accuracy, completeness, or usefulness of any information, apparatus, product, or process disclosed, or represents that its use would not infringe privately owned rights. Reference herein to any specific commercial product, process, or service by trade name, trademark, manufacturer, or otherwise, does not necessarily constitute or imply its endorsement, recommendation, or favoring by the United States Government or the University of California. The views and opinions of authors expressed herein do not necessarily state or reflect those of the United States Government or the University of California, and shall not be used for advertising or product endorsement purposes.

This report has been reproduced directly from the best available copy.

Available to DOE and DOE contractors from the Office of Scientific and Technical Information P.O. Box 62, Oak Ridge, TN 37831

Prices available from (423) 576-8401

Available to the public from the National Technical Information Service

U.S. Department of Commerce 5285 Port Royal Rd., Springfield, VA 22161 


\title{
A conceptual design for an electron beam
}

\author{
Manuel Garcia \\ 15 February 1999
}

Lawrence Livermore National Laboratory, L-153, POB 808 Livermore, CA 94551-0808 USA

(925) 422- 6017, garcia22@1lnl.gov, FAX (925) 423-5080

This report is a brief description of a model electron beam, which is meant to serve as a pulsed heat source that vaporizes a metal fleck into an "under-dense" cloud. See Reference 1. The envelope of the electron beam is calculated from the paraxial ray equation, as stated in Reference 2. The examples shown here are for $5 \mathrm{~A}, 200 \mathrm{keV}$ beams that focus to waists of under $0.4 \mathrm{~mm}$ diameter, within a cylindrical volume of $10 \mathrm{~cm}$ radius and length. The magnetic fields assumed in the examples are moderate, $0.11 \mathrm{~T}$ and $0.35 \mathrm{~T}$, and can probably be created by permanent magnets.

This report is a sequence of captions describing the five figures.

\section{Figure 1: Normalized beam energy and axial B-field.}

A cathode plasma of $2 \mathrm{~mm}$ diameter is created by some means, such as resistively heating a thoriated tungsten plate, discharging a hollow cathode, or illuminating the cathode with a small, pulsed YAG laser (a very neat method). A voltage pulse draws electrons from this plasma into the volume of the electron beam model, which extends axially from the cathode at $z=0$, to $Z=100 \mathrm{~mm}$, and radially to $100 \mathrm{~mm}$. The electrons are assumed to be injected into the paraxial model volume with the following initial parameters: $5 \mathrm{~A}, 100 \mathrm{eV}$ of kinetic energy, and an emittance parameter $\varepsilon=2 \times 10^{-4}$ angle* $\mathrm{m}$. Electrons are accelerated by $200 \mathrm{kV}$ between $0<Z<10 \mathrm{~mm}$, the ChildLangmuir limit for this gap is $6.5 \mathrm{~A}$. An axial magnetic field is created by ten coils of $100 \mathrm{~mm}$ radius, placed between $Z=40 \mathrm{~mm}$ and $z=60 \mathrm{~mm}$. Another single coil of $2 \mathrm{~mm}$ radius circles the cathode spot, and has a reverse polarity that cancels the field at $z=0$ (to within several gauss). In this paraxial model, the magnetic field at any $z$ is assumed to be that along the axis at that $z$. 


\section{Figure 2: Electron beam envelope for example 1.}

Example 1 has solenoid coils with currents of $1800 \mathrm{~A}$ (and a compensating coil current of -257 A). The peak axial magnetic induction is $0.112 \mathrm{~T}$ (1120 gauss). The magnetic field of this example can be produced by cylindrical permanent magnets. The envelope first expands then contracts to a waist nearly $100 \mathrm{~mm}$ from the cathode. A metal fleck vaporized and heated at this waist would have at least $4 \mathrm{~cm}$ of empty space around it, aside from its support.

\section{Figure 3: Electron beam waist for example 1 .}

The figure shows a close-up view of the beam waist for example 1 . The locations of calculated points are shown. The entire calculation includes 10,000 points along $z$. The copper fleck described as an example in Reference 1 has a radius of $0.08 \mathrm{~mm}$ and a thickness of $0.023 \mathrm{~mm}$. Such a fleck at the waist would intercept much of the beam, and vaporize quickly before expanding beyond the electron beam. See Reference 1 on this point.

\section{Figure 4: Electron beam envelope for example 2 .}

Example 2 has solenoid coils with currents of 5600 A (and a compensating coil current of $-800 \mathrm{~A}$ ). The peak axial magnetic induction here is $0.35 \mathrm{~T}$ (3500 gauss). All other parameters are the same as in example 1 . This magnetic field can probably also be created with commercial permanent magnets. Cylindrical permanent magnets would simplify an actual device, and if they have an outside diameter under $300 \mathrm{~mm}$ then this device would slide within the bore of the Diagnostic Instrument Manipulators (DIM) planned for NIF. The DIMs are hollow "robotic" arms that will be used to introduce and position instrumentation within the NIF target chamber. The electron beam focuses more often with a higher magnetic field, in this example three waists occur by $Z=100 \mathrm{~mm}$. 


\section{Figure 5: Electron beam waist for example 2.}

The figure shows a close-up view of the beam waist for example 2 . The third waist looks like the waist of example 1, shifted outward by $1 \mathrm{~mm}$. Because of the higher magnetic field, the electron beam in example 2 never widens to the extent of the electron beam in example 1.

\section{Summary}

It seems possible to deliver, by an electron beam, tens of millijoules of heat to metal flecks of sub-millimeter extent, within tens of nanoseconds, within reasonable dimensions, and with simple magnets. This idea merits further study if there is an advantage to generating under-dense radiators in laser-fusion facilities.

\section{References}

$1 \quad$ M. Garcia, "Creating metallic under-dense radiators by electron beam heating prior to laser impact," 15 December 1999.

2 S. Humphries, Jr., Charged Particle Beams, NY: John Wiley \& Sons, Inc., 1990, see section 9.2, pages 400-402. 


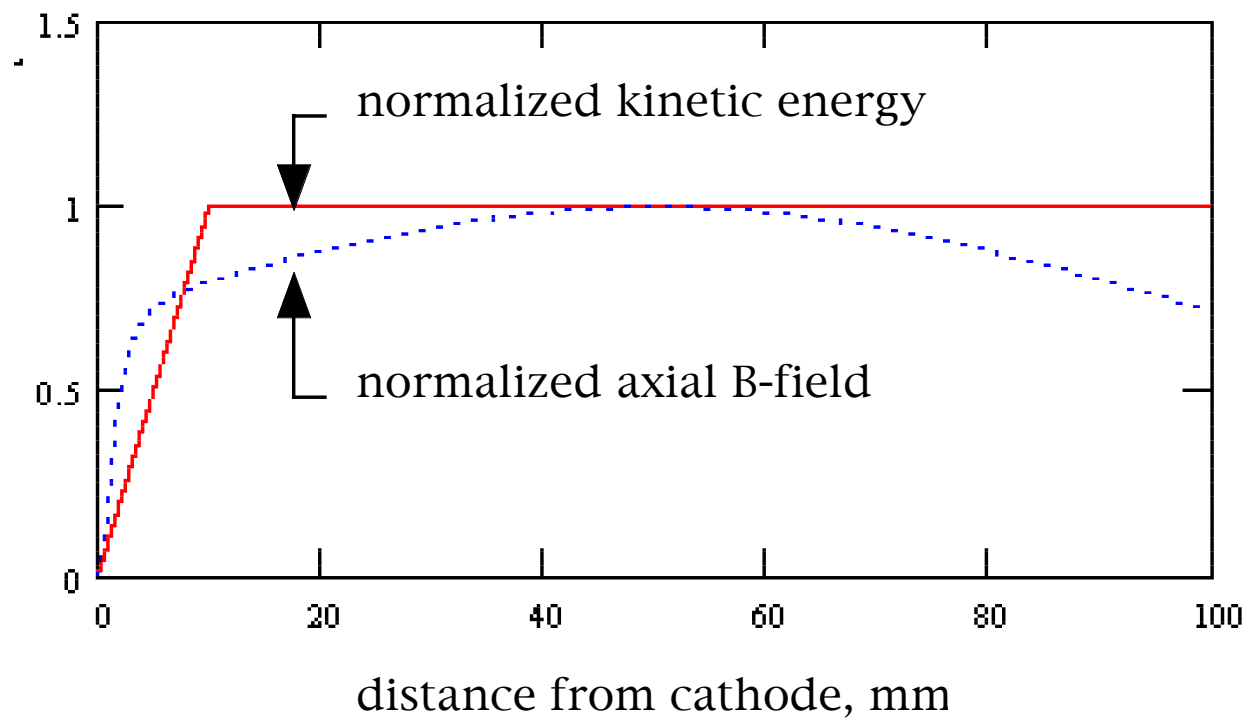

Figure 1. Normalized beam energy and axial B-Field. example 1: $\mathrm{E}_{\max }=200 \mathrm{keV}, \mathrm{B}_{\max }=0.112 \mathrm{~T}$, example 2: $\mathrm{E}_{\max }=200 \mathrm{keV}, \mathrm{B}_{\max }=0.350 \mathrm{~T}$, both: $\mathrm{I}=5 \mathrm{~A}, \varepsilon=2 \times 10^{-4}$ angle* $\mathrm{m}, \mathrm{E}(0)=100 \mathrm{eV}$ 


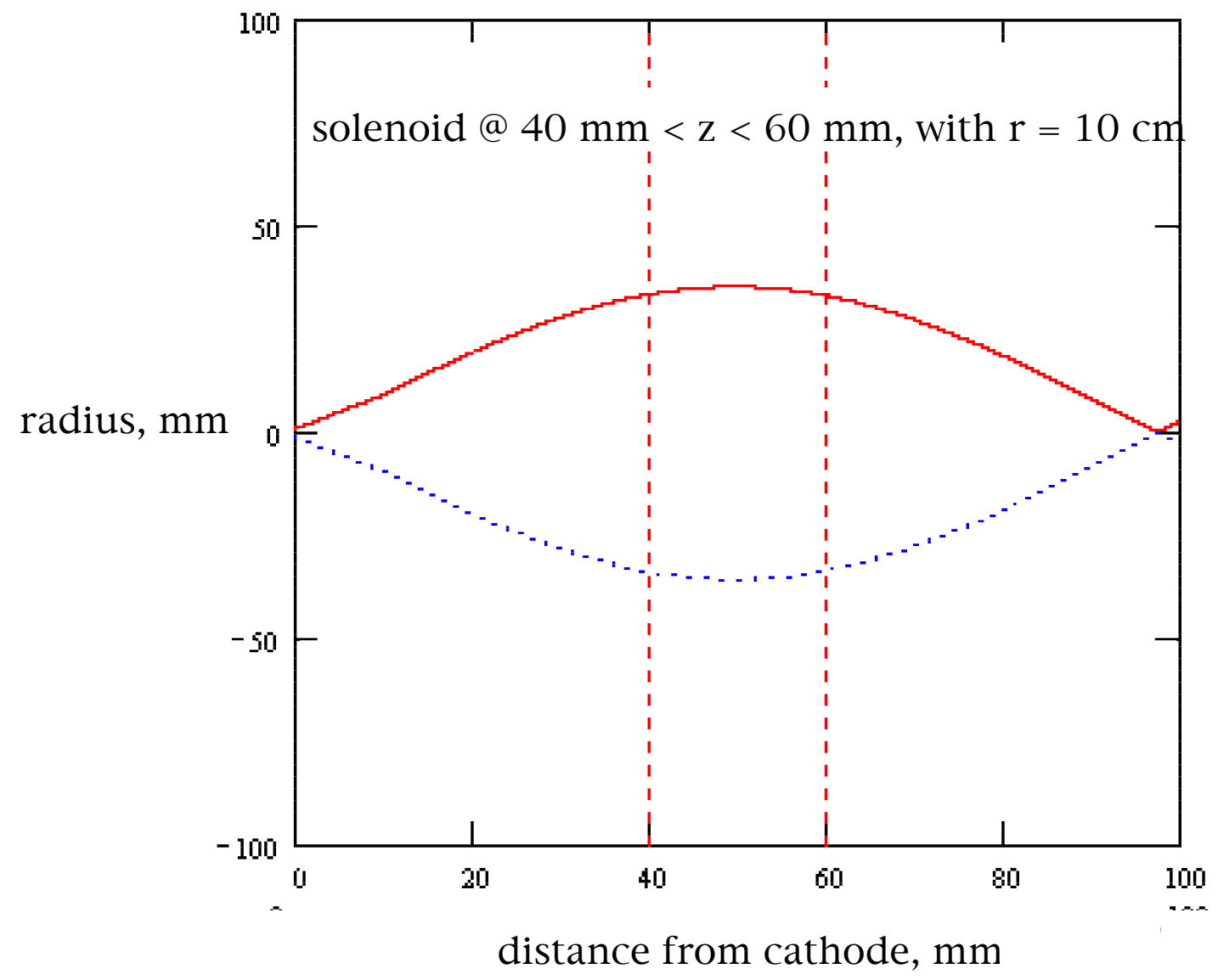

Figure 2: Electron beam envelope for example 1.

@ $\mathrm{z}=0: \mathrm{r}=1 \mathrm{~mm}, \mathrm{I}=5 \mathrm{~A}, \varepsilon=2 \times 10^{-4}$ angle $\mathrm{m}, \mathrm{E}=100 \mathrm{eV}$; $200 \mathrm{kV}$ acceleration by $\mathrm{z}=10 \mathrm{~mm}$ ( $<$ Child-Langmuir); peak axial $\mathrm{B}$-field $=0.112 \mathrm{~T},(\mathrm{~B}(0)<10$ gauss, by small coil $)$ 


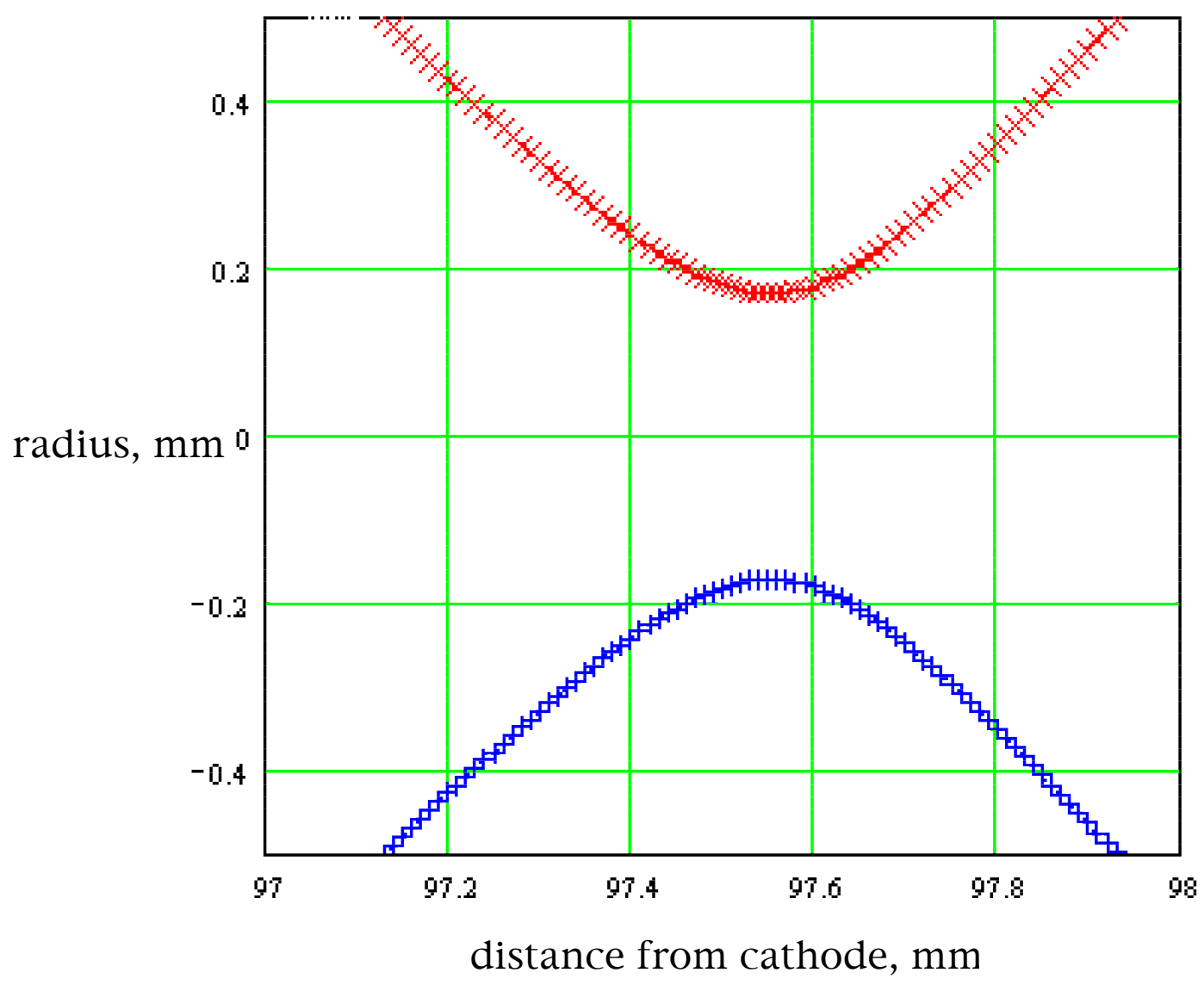

Figure 3: Electron beam waist for example 1. Beam waist is limited by $\varepsilon$ and $\mathrm{B}(0)$; the locations of calculated points are shown. $\mathrm{r}(0)=1 \mathrm{~mm}, \mathrm{I}=5 \mathrm{~A}, \varepsilon=2 \times 10^{-4}$ angle* $\mathrm{m}, \mathrm{E}(0)=$ $100 \mathrm{eV}, \mathrm{E}(\mathrm{z}>10 \mathrm{~mm})=200 \mathrm{keV}, \mathrm{B}_{\max }=0.112 \mathrm{~T}$, $(\mathrm{B}(0)<10$ gauss, by a small reverse coil) 


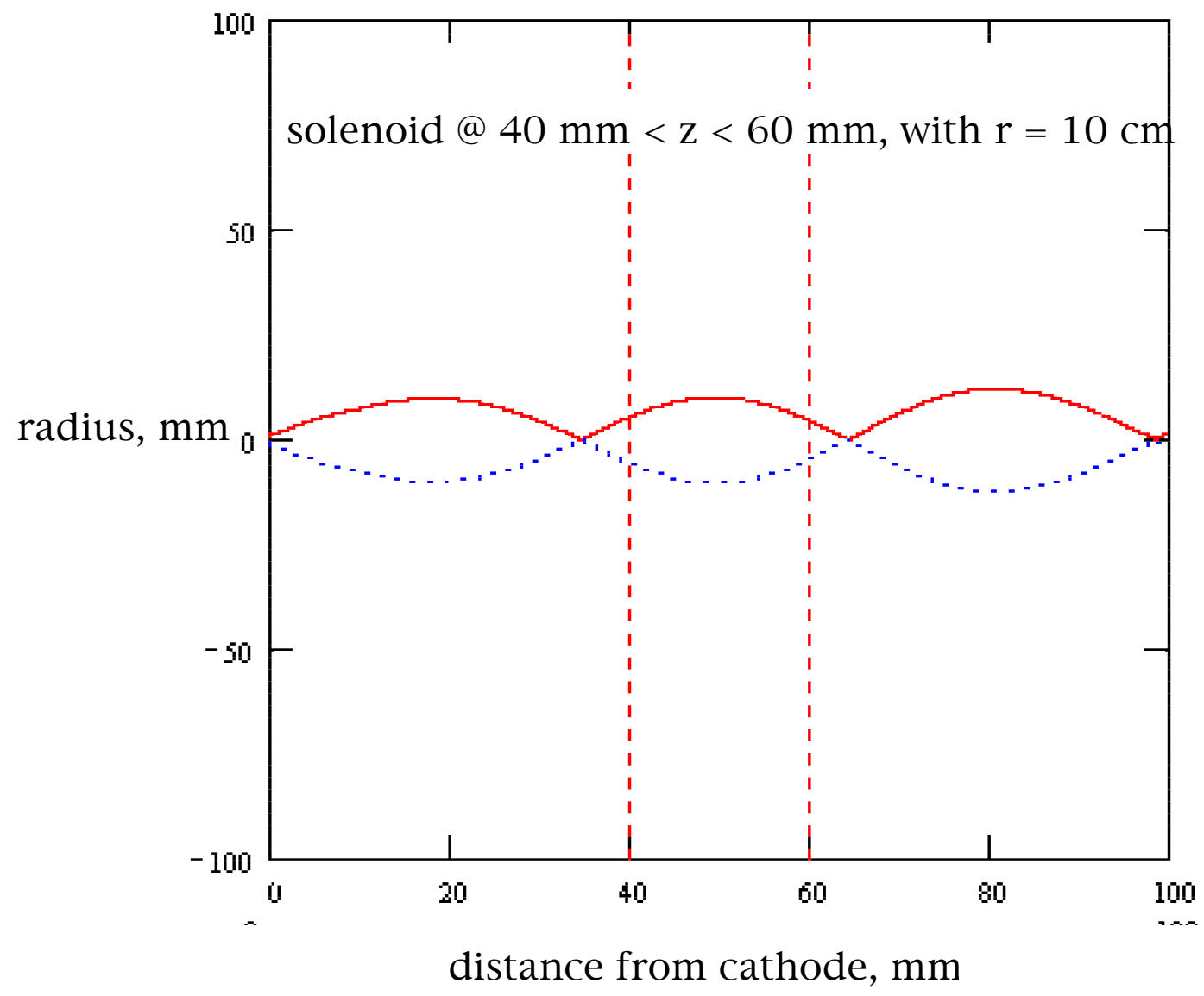

Figure 4: Electron beam envelope for example 2.

@ $\mathrm{z}=0: \mathrm{r}=1 \mathrm{~mm}, \mathrm{I}=5 \mathrm{~A}, \varepsilon=2 \times 10^{-4}$ angle* $\mathrm{m}, \mathrm{E}=100 \mathrm{eV}$; $200 \mathrm{kV}$ acceleration by $\mathrm{Z}=10 \mathrm{~mm}$ ( $<$ Child-Langmuir); peak axial $\mathrm{B}$-field $=0.350 \mathrm{~T},(\mathrm{~B}(0)<10$ gauss, by small coil $)$ 


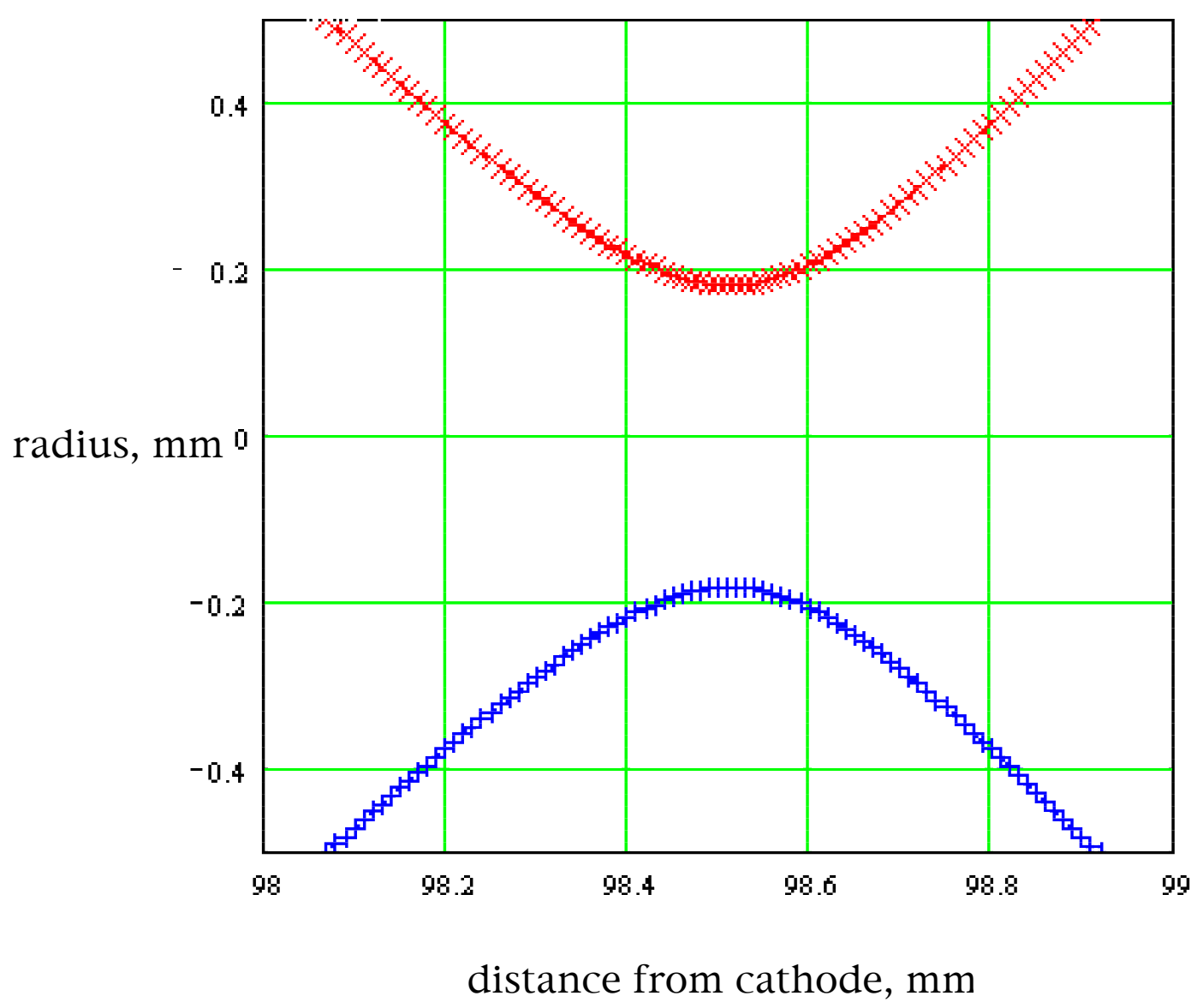

Figure 5: Electron beam waist for example 2 Beam waist is limited by $\varepsilon$ and $\mathrm{B}(0)$; the locations of calculated points are shown. $\mathrm{r}(0)=1 \mathrm{~mm}, \mathrm{I}=5 \mathrm{~A}, \varepsilon=2 \times 10^{-4}$ angle* $\mathrm{m}, \mathrm{E}(0)=$ $100 \mathrm{eV}, \mathrm{E}(\mathrm{z}>10 \mathrm{~mm})=200 \mathrm{keV}, \mathrm{B}_{\max }=0.350 \mathrm{~T}$ $(\mathrm{B}(0)<10$ gauss, by a small reverse coil ) 